\title{
Urdimento
}

Revista de Estudos em Artes Cênicas

E-ISSN: 2358.6958

\section{Pelo movimento dançado: Uma gestologia do cacoete}

\author{
Zilá Muniz
}

Amanda Gois

\section{Para citar este artigo:}

MUNIZ, Zilá; GOIS, Amanda. Pelo movimento dançado:

Uma gestologia do cacoete. Urdimento, Florianópolis,

v. 1, n. 40, mar./abr. 2021.

do) DOI: http:/dx.doi.org/10.5965/1414573101402021e0110

Este artigo passou pelo Plagiarism Detection Software | iThenticate 
Pelo movimento dançado: Uma gestologia do cacoete

Zilá Muniz $^{1}$

Amanda Gois ${ }^{2}$

\begin{abstract}
Resumo
Este artigo propõe pensar o movimento da improvisação em dança com o movimento repetitivo, mais especificamente do cacoete, no caso aqui, proveniente da Sindrome de Tourette em um exercício de cruzar aspectos tanto da dança em relação ao cacoete, quanto do cacoete com a dança. Como a dança, enquanto prática e pensamento, pode ser desafiada pela percepção sensório motora do cacoete? Para tal, o enfoque é a relação entre a percepção sensorial e a criação do gesto, ao provocar um princípio de definição para uma gestologia do cacoete pela perspectiva do movimento dançado.
\end{abstract}

Palavras-chave: Sindrome de Tourette. Gestologia. Improvisação em dança.

By the danced movement: A gestology of twitch

\begin{abstract}
This article proposes to think the movement of improvisation in dance with repetitive movement, more specifically from twitches, in this case, coming from Tourette's syndrome in an exercise of crossing aspects of both dance in relation to twitch, and twitch with dance. How dance, as a practice and thought, could be challenge by the sensorimotor perception of twitch? For this, the focus is the relationship between sensory perception and the creation of the gesture, by provoking a principle of definition for a gestology of twitch from the perspective of the dance movement.
\end{abstract}

Keywords: Tourette's syndrome. Gestology. Improvisation in dance.

1 Doutora em Teatro pela Universidade do Estado de Santa Catarina (2014), Coreógrafa do Ronda Grupo desde 1999, desenvolve pesquisa em improvisação como processos de composição em dança. Explora possibilidades e estratégias de co-composição emergente de eventos coreográficos em espaços da cidade. Realizou estágio doutoral na Concordia University em Montreal, durante o doutorado com bolsa da Capes. Passou a integrar o SenseLab Laboratory for Thought in Motion, Montreal/CA, como colaboradora internacional. Professora Colaboradora na graduação Licenciatura em Teatro - UDESC desde 2017. zilamuniz@hotmail.com

(9) http://lattes.cnpq.br/5890040270115363 (iD https://orcid.org/0000-0001-5315-0393

2 Graduada em Licenciatura em Teatro pela Universidade do Estado de Santa Catarina (2019), dançarina de contato improvisação, organiza e facilita eventos e aulas de dança, como o Andanças Poéticas na Cidade. Investiga processos de improvisação e composição do movimento, engajada na questão do gesto. fg.amanda.ag@gmail.com

(9) http://lattes.cnpq.br/3915588263626303

https://orcid.org/0000-0002-5308-1954 
Para el movimiento danzado: Una gestología del tic

\section{Resumen}

Este artículo propone pensar el movimiento de improvisación en la danza con movimiento repetitivo, más específicamente del tics, en este caso, proveniente del Sindrome de Tourette en un ejercicio de cruce de aspectos tanto de la danza en relación al tic, como del tic con la danza. ¿Cómo puede la danza, como práctica y como pensamiento, ser desafiada por la percepción sensorio motora del tic? Para ello, el foco es la relación entre la percepción sensorial y la creación del gesto, al provocar un principio de definición para una gestología del tic desde la perspectiva del movimiento danzado.

Palabras clave: Síndrome de Tourette. Gestología. Improvisación en danza. 
Sonhei

Estava dirigindo e atuando em uma peça de dança junto com o meu tio.

No sonho, os espectadores me falavam.

Vocês precisam dançar, vocês têm que dançar.

Dançamos toda a estrutura incontrolável dos neurônios "nanan" "nanan" gaguejava.

Conforme isso, movimentos abruptos e espontâneos com o braço "popopopo".

Ele ia se libertando, se libertando, se libertando até morrer.

Ele morre na cena.

Deitado, leve, livre e suave.

Um sorriso de liberdade, e morre.

Morre caindo nas minhas mãos.

Há um desejo pela morte.

A dança da liberdade fez ele morrer.

Quando não mais havia espaço para a repressão dos impulsos nervosos e musculares exigidos pelo corpo não disciplinado e controlado pela esfera da quietude que vigia a neuro normalidade, o corpo cai, e em queda morre.

Por que eu te fiz dançar?

\section{Movimento como inquietude}

Esta pesquisa propõe pensar o movimento da improvisação em dança com o movimento repetitivo, mais especificamente do cacoete3, no caso aqui, proveniente da Síndrome de Tourette em um exercício de cruzar aspectos tanto da dança em relação ao cacoete, quanto do cacoete com a dança. Algumas questões são centrais para a realização da reflexão sobre os dois fenômenos distintos, a improvisação e o cacoete. Podem práticas de improvisação em dança contribuir com experiências de subjetivação para pessoas que são diagnosticadas com Síndrome de Tourette? Como a dança, enquanto prática e pensamento, pode ser desafiada pela percepção sensório-motora do cacoete? Para tal, faz-se uma incursão breve no que é a Síndrome de Tourette, cria-se relações entre a improvisação em dança e a criação do gesto, com o desejo de encontrar um princípio do que possa ser uma gestologia do cacoete.

\footnotetext{
${ }^{3}$ Ana Gabriela Hounie (2012), define os tiques como movimentos simples e abruptos, que são repetitivos e curtos, podem ser motores ou vocais, voluntários e involuntários, decorridos de uma sensação premonitória. Tanto a nomenclatura tique, quanto cacoete, referem-se a uma mesma coisa, sendo cacoete o termo mais popular. Nem todo movimento repetitivo é um tique, o que caracteriza o tique ou o cacoete, portanto, são sensações premonitórias ou fenômenos sensoriais que o antecedem (Hounie, 2012, p. 19).
} 
Ao encontro do sonho, descrito acima, os aprendizados na universidade e a insurgência da vida com meu Tio V., com quem convivi durante minha infância, tive a possibilidade de conectar questionamentos sobre a peculiaridade do seu mover. Crescemos juntos, meu tio e eu, ele é quatro anos mais velho, convivemos na mesma casa e fomos criados como irmãos. Ele foi o exemplo em que eu me espelhava para crescer, sempre brincamos com nossa singularidade de movimentos, caretas em fotografias e jogos na rua.

Demorei muito tempo para perceber que havia algo distinto na forma como ele se movia e como este movimento era recebido pelas outras pessoas, principalmente na sua dificuldade de adaptação na escola, pois, ele foi expulso de todas as escolas em que foi matriculado. Fato é que as escolas que ele frequentou não tinham informação e recursos suficientes para acolher os comportamentos imprevisíveis do Tio V. A família também não foi devidamente preparada para lidar com tal situação, ainda que tenham procurado os mais variados recursos e tratamentos com psicólogos, psiquiatras, centros espíritas, orações católicas e outros. Inclusive eu lembro muito bem de uma passagem que ilustra esta questão, um padre dizendo que ele era como uma esponja das energias negativas. O Tio V. estava sempre em um lugar de beira, nem na margem e nem no centro, no sofrimento da incompreensão do seu mover-se e de como isso era invisibilizado por parte da família.

Por volta dos seis anos de idade o Tio V. foi diagnosticado com a Síndrome de Tourette, que se manifestava nele por meio da extrema inquietude e uma certa hiperatividade que aparecia nas caretas, no soltar palavras intermitentemente antes de dormir e também quando repetidamente fungava quando se sentia desconfortável ou constrangido. Agora, imagine-o dentro de um espaço onde a restrição dos movimentos é a regra, como uma sala de aula, tendo que passar ali uma boa parte do dia e, sem poder controlar, ele realizava movimentos e sons exagerados e incomuns para aquele ambiente. Movimentos como um bater de asas rápido e repetitivo, ou um soltar palavras do nada durante o exercício de uma aula, ou uma dificuldade em expressar o que estava acontecendo por conta da gagueira. 
Aos poucos fui percebendo que o Tio V., que faz o movimento do beija-flor da capoeira e que tem uma percepção corporal ativa, encontrou nas artes do movimento um espaço de repouso para seu corpo. Ele vive constantemente num estado de quem vai realizar algum movimento involuntário e repetitivo. Nesse estado de percepção sensório motor, sem a medição da consciência que permite uma escolha, vem o afeto e a sensação que é o que dispara o gatilho, e depois um impulso em direção à incipiência e concrescência de um gesto fragmentado do movimento.

De acordo com Ana Gabriela Hounie (2012), no livro Tiques, Cacoetes, Síndrome de Tourette, a criança por volta dos 10 anos de idade, diagnosticada com Sindrome de Tourette, na maior parte dos casos, antes da manifestação do tique ou do cacoete acontecer, já percebe 'sensações premonitórias', algo que é sentido segundos antes de o tique ocorrer. Tais sensações são percebidas tanto na região do corpo onde o tique está para acontecer, “[...] como uma 'coceira' ou um formigamento, como podem ocorrer em um lugar inespecífico, como uma 'sensação mental' ou algo entre o físico e o mental” (Hounie, 2012, pg.20). As características desse fenômeno sensorial que antecedem o tique, podem ser o fio que conecta a criação do gesto com o movimento dançado.

Ainda na minha infância, em algum momento, percebi que os gestos do Tio V. são inaceitáveis comparados aos gestos padronizados e cotidianos regulados por uma coreografia social. Também tomei consciência de que os tiques nervosos ou cacoetes, são gestos que se aproximam de um quase gesto extra cotidiano, um quase gesto do equilíbrio precário. O conceito de equilíbrio precário é um dos princípios levantados pelo teatrólogo Eugenio Barba (1995) para gerar um estado de presença cênica do ator e da atriz em cena e que traz como base para o trabalho a ideia de que a todo momento se está prestes a perder o equilíbrio e em constante atenção psicofísica. O modo de se manter neste estado garantiria um corpo dilatado e vivo que apresenta-se como um foco de energia e potência. Portanto, no caso do Tio V., percebe-se, que em alguns momentos este estado de corpo ocorre nele. Contudo, quando os cacoetes surgem entre seus gestos cotidianos, o movimento se transforma, deixa de ser um gesto cotidiano sem vir a 
ser também um gesto extra cotidiano.

Um dia, por volta dos meus nove anos de idade, perguntei para minha família por que as pessoas não aceitavam ou entendiam o meu tio e eles me falaram da Sindrome de Tourette (ST). Fui pesquisar e encontrei poucas informações a respeito da ST. Curiosa, já na adolescência, decidi ler a bula de um dos remédios que ele tomava. Fiquei assustada com as indicações que descrevem sintomas que eu não via no meu tio, inclusive com riscos para a sua saúde. Brincávamos muito, eu e ele, devido à pequena diferença de idade entre nós. Eu imitava seus gestos associados ao processo de descoberta do meu próprio corpo e dos movimentos quando criança, assim, movia também repetidamente meus braços, sobrancelhas, fazia caretas e alterava a voz.

A partir da convivência e de uma percepção mediada por esta presença que foi o Tio V., esta pesquisa se origina, quando entre ensaios e memórias trago à luz a Sindrome de Tourette, ao buscar possibilidades de relação entre a improvisação em dança e o cacoete. A Síndrome de Tourette é um distúrbio neuropsiquiátrico que causa movimentos repetitivos, sons indesejados e geralmente se inicia ainda na infância.

O fenômeno sensorial é descrito como: “[...] sentimentos ou sensações desconfortáveis que precedem os tiques, geralmente sendo aliviados com o movimento" (Hounie, 2012, p. 20). Ela o separa em dois grupos: o primeiro são as sensações corporais que ocorrem antes do tique acontecer e pode ser em todo o corpo ou em partes do corpo; o segundo são as sensações mentais que ocorrem enquanto o tique acontece sem um local específico.

A origem do nome Síndrome de Tourette vem do neurologista Francês Georges Gilles de La Tourette, que aprofundou o diagnóstico dos sintomas para um quadro clínico específico (Rosário, M.C; Mathis, M.A.; Miguel, E.C., 2012, p. 29). De acordo com Ana Gabriela Hounie (2012), um fator que define a necessidade de tratamento na pessoa diagnosticada é o impacto social que os sintomas podem ter em sua vida. 
Para receber esse diagnóstico, é necessária a presença de tiques vocais e motores durante a evolução da doença, que devem durar pelo menos um ano e ter um impacto na vida do paciente. Esse critério de "impacto" provavelmente será modificado nas classificações futuras, pois uma pessoa pode ter ST sem que isso seja um problema para ela (Hounie, 2012, p. 22).

Sendo assim, percebo um ponto que impulsiona a pesquisa da improvisação em dança com a da Síndrome de Tourette, a questão do impacto social, ao buscar por processos práticos que relacionam o comportamento repetitivo do cacoete com o movimento dançado. Assim também, como permitir que a arte e a dança possam olhar para tais comportamentos repetitivos de outro modo, na medida em que tem seus fundamentos de criação desafiados por outras perspectivas do movimento. Adentro em tal discussão sobre o gesto e sobre o cacoete, por meio de três formas de pensamento: a filosofia, a ciência e a arte, como argumenta o pesquisador, arquiteto Pasqualino Romano Magnavita em seu artigo Gestologia: Breve ensaio sobre uma diferente teoria do gesto, publicado na revista Corpocidade 5 - Gestos Urbanos:

Pode-se afirmar que a Filosofia tem como objetivo traçar um Plano de Imanência e criar conceitos. A ciência, por sua vez, tem como objetivo traçar um Plano de Referência e criar funções (functivos). A arte visa traçar um Plano de Composição e criar percepções (perceptos) e afetos. Os conceitos registram variações; as funções registram variáveis e as percepções e afetos expressam variedade (Magnavita, 2017, p. 210).

Deste modo, o gesto pode ser entendido como o cruzamento entre estas três vertentes do pensamento: o filosófico, o científico e o artístico. Um processo criativo que investiga o cacoete, o vê como uma variedade perceptiva e afetiva da criação, ainda que neste caminho, estejam entrelaçados os lugares filosóficos e científicos da gestologia como dobraduras de si.

O que alça a duração entre o interior/exterior pela criação de uma gestologia de si por meio da dança, pode ser compreendido com o conceito de Ritornelo, que é a própria expressividade rítmica presente nos movimentos das dobras, neste caso, nas dobras da dança e da escrita: "A territorialidade é o ato rítmico tornado expressivo" (Magnavita, 2017, p. 217). É atribuída ao Ritornelo: "O território seria o 
efeito da arte, e o gesto tem expressão enquanto arte" (ibidem.). Logo, percebo que é um marco territorial que diferencia o cacoete de um gesto cotidiano, que diferencia um gesto cotidiano de um gesto dançado, esse marco territorial acontece principalmente mediante a expressão rítmica do gesto.

Em 2018, em um exercício na função de direção, foi realizada a pesquisa e criação de um processo artístico, intitulado Sanação no5, durante a disciplina de Direção Teatral I e II, parte do currículo da graduação em Licenciatura em Teatro da Universidade do Estado de Santa Catarina, a partir das seguintes questões: O que move o movimento do cacoete? Como a criação de uma ecologia de afetos influi na criação do gesto e de que forma se relaciona com o movimento dançado?

Na possibilidade de conduzir a criação de uma direção teatral com um viés pedagógico, cada encontro do Sanação no5 aconteceu mais com características de um jogo lúdico e como um ato poético, do que como ensaio para uma apresentação. Assim, a proposta foi a de perceber cada encontro como um momento para a invenção de si e do outro no mundo, um espaço ritual para se viver a instauração de outro tempo, um momento para permitir que o acontecimento se tornasse experiência. Mais do que encontros para se chegar a um produto, os ensaios aconteceram já como um fim em si. A apresentação final de Sanação no5 foi uma abertura para compartilhar tais finitudes, nas quais pesquisamos o que precede a criação do gesto durante a improvisação em dança.

Durante o processo da pesquisa, o meu tio $V$. pode participar de cinco encontros, nos quais realizamos propostas de relaxamento, de improvisação em dança e dinâmicas que exercitam a atenção pelo movimento. Ao fim, ele expressou que se sentia muito mais tranquilo depois de cada encontro e sobre a questão volicional do tique, que não vem tanto de uma involuntariedade do movimento, mas que ele acontece precedido por uma sensação. Compreendi essa sensação, como 'algo' que beira o movimento. Por meio dessa fala, conduzi os próximos encontros na busca do elo entre sensação e movimento.

A partir de tal elo, encontrei o que justifica a escolha pela prática da improvisação em dança e o que a relaciona com o cacoete, o fenômeno 
sensorial. Desse modo, ao invés de propor uma prática de dança para criar uma coreografia de gestos dançados inspirados no tique, a proposta foi trabalhar com estímulos e sensações que antecedem a criação do gesto durante uma improvisação.

Para tanto, foram realizadas distintas dinâmicas, tanto em salas de dança, quanto em quintais, tanto em silêncio, quanto com música. Por exemplo, trazer a atenção para textura do pisar na grama; andar com diferentes apoios do corpo; registrar muscularmente a influência do ambiente na sensação corporal e mental, por meio de uma leve contração de todo o corpo; ao fim de cada encontro, um momento de improvisação livre e de conversa.

Dentre outras proposições, foram realizados exercícios de repetição contínua de movimentos do cotidiano, por exemplo, o ato de varrer a sala, observar como a repetição de um movimento simples afeta a sensação do movimento. Finalizar com um registro poético em palavras, imagens, ou gestos que poderiam cartografar as sensações que atravessaram o corpo durante os exercícios.

Outro momento interessante foi o de ficar imóvel, dançar, pausar o movimento, iniciar o movimento apenas quando o corpo não aguentar mais a necessidade de se mover. Outro foi de propor uma meditação na qual era permitido o movimento, e ninguém se movimentou.

Gostaria que esse trabalho pudesse servir como incentivo para futuras pesquisas de dinâmicas e de propostas de improvisação em dança, com pessoas que tenham a Síndrome de Tourette, a fim de compreender os fenômenos sensoriais que precedem o cacoete e também com dançarinos que estejam interessados em investigar a percepção sinestésica do movimento.

\section{Gestologia do cacoete}

O conceito de artisticidade, descrito no livro Always more than one da filósofa e artista canadense Erin Manning (2013) vem da tradução de artfulness, permeia o fazer artístico que proponho no presente estudo para uma arte como meio. "O que mais pode a prática artística se tornar quando os objetos não são a meta, mas o ativador, o condutor para novos modos de existência?4" (2013, p. 47). Compreendo

\footnotetext{
${ }^{4}$ What else can artistic practice become when the objects is not goal, but the activator, the conduit toward
} 
como uma proposta artística na qual a arte é tomada como caminho, como o meio do movimento da experiência e não como um processo para um fim ou um objeto a ser produzido.

A artisticidade acontece durante o processo de concepção de uma dramaturgia de dança, no qual práticas de um pensamento em ação podem ser disparadores da experiência em artisticidade. A partir do desdobramento de tal conceito, é possível uma prática de direção que se comunique com a improvisação em dança e com o movimento repetitivo? Como se posiciona a estética e a política, a ética e a experiência em uma prática artística e pedagógica? Percebo que, por intermédio, a artisticidade emerge da busca por uma performatividade prática do pensamento sobre a dança.

A partir de tal perspectiva, permito-me atravessar pelos escritos de Erin Manning para relacionar como o conceito de artisticidade inspirou a prática artística do Sanação no5. No livro The Minor Gesture (2016), Manning traz a experiência vivida de Ido Kedar, um garoto autista que se comunica por intermédio do computador sobre sua percepção de mundo e, pela narração dele, ela discorre sobre outros dois conceitos fundamentais para esta pesquisa, o de neurotipicidade e neurodiversidade:

O mundo em que vivemos, neurotipicamente orientado, privilegia a consciência como alinhada à instrumentalidade e não a tendências nãoconscientes e não-convencionais. É essa perspectiva bem neurotípica que nos ensina que um corpo começa e termina em um envelope de pele que podemos perceber prontamente5 (Manning, 2016, p.114).

Dessa maneira, percebi que situar a neurodiversidade como uma possível relação de transformação do movimento, das noções sociais e políticas que permeiam as corporalidades, torna-se mais do que necessário. A vivência com o Tio V. durante minha infância e adolescência foi importante no sentido do que Erin

to new modes of existence? (Tradução nossa)

${ }^{5}$ The neurotypically- oriented world we live in privileges consciousness as aligned to instrumentality over nonconscious, nonvolitional tendings. It is this very neurotypical perspective that teaches us that a body begins and ends in a skin envelope we can readily perceive. (Tradução nossa) 
Manning apresenta sobre a experiência neurotípica para a criança quando ela está descobrindo o mundo.

De novo e de novo, na infância, estamos dando instruções que nos ajudam a diferenciar nossa pele daquela do mundo. Esses ensinamentos, que também tendem a forjar normativamente o racional sobre o emergente criativo ou intuitivo, o individual sobre o relacional, sintonizam nossa existência em direção a uma noção muito simples do que um corpo pode fazer6 (Manning, 2016, p. 114).

Como eu me inspirava muito no tio $V$. para correr, jogar e brincar, o seu movimento peculiar me possibilitou apreender, mesmo sem perceber, outras camadas sobre o que um corpo pode fazer. Desde cedo aprendi a jogar com tais camadas, pois era justamente o que meu tio fazia ao romper com os padrões de movimento cotidianos, ao instaurar, devido à Síndrome de Tourette e com a influência do ambiente onde vivíamos, outros movimentos que rompiam com tais padrões. Principalmente em relação ao ritmo, pois o tique ou o cacoete tem qualidades de acentuação rítmica muito distintas daquelas percebidas em um gesto cotidiano.

Crescer com meu Tio V. me ensinou outras noções e possibilidades do que um corpo pode fazer e isso era impressionante, eu o admirava. Pode-se dizer que a memória dessa vivência foi despertada em mim por meio da dança como experiência de se mover no mundo. Na introdução da chave de abertura de seu livro, The Minor Gesture, Manning (2016) aponta “[...] nós já estamos situados, alinhados em oposição ao ideal de vida dominante, ao discurso majoritário neurotípico, e ficamos aquém.”7 (2016, p. 4). Os trabalhos e pesquisas da autora foram especificamente realizados com pessoas diagnosticadas com espectro autista, portanto, trabalho a percepção e desloco tais noções na vivência artística com pessoas diagnosticadas com síndrome de Tourette. Como investigar o

${ }^{6}$ Again and again in young childhood we are giving instructions that assist us in differentiating our skin from that of the world. [...]. These teachings, which also tend to foreground the normatively rational over the emergently creative or intuitive, the individual over the relational, tune our existence toward a very simple notion of what a body can do. (Tradução nossa)

[...]we have already been situated, aligned in opposition to the dominant ideal of life, to the marjoritan discourse of neurotypically, and we fall short. (Tradução nossa) 
movimento involuntário do cacoete pela improvisação em dança?

Em relação à neurodiversidade e aos desdobramentos de um pensamento coreográfico sobre mundo em corpo e corpo em mundo Manning apresenta:

Se o corpo é uma constelação dinâmica em co-composição com o meio ambiente, se é uma ecologia de práticas, e se o pensamento é um contribuidor ativo para a sensação da experiência, parece-me que o ponto de partida para desafiar a separação do corpo-mundo é colocar o pensamento no mundo. O pensamento como a experiência de Kedar não está "em" seu corpo. É através da experiência, nas sensações sinestésicas que refutam a localização absoluta do corpo e do mundo8 (Manning, 2016, p. 115).

Tal pensamento sobre um corpo que se estende, que é o mundo, dialoga com outros autores que apresento no decorrer deste trabalho e que vão co-compondo um fazer/pensar artístico que se desdobra também nas práticas. Práticas tais como a improvisação em dança e o contato improvisação que são parte fundamental da direção teatral e dos eventos coreográficos criados. Logo, a experiência neurotípica é apenas um dos recortes da multiplicidade de sensações sinestésicas que se desdobram no corpo, multiplicidade neurodiversa e muitas vezes, não habitual. As quais, são constantemente denunciadas pelas normas do registro hegemônico neurotípico e que podem ser resgatadas e amplificadas através da arte. A experiência vivida de ser corpo em mundo é a diversidade das neurotransmissões do sistema muscular até os sistemas políticos.

Como referência teórica incluo o ensaio intitulado Modes of Thought (1968) do filósofo e matemático britânico Alfred North Whitehead, no qual encontro uma estrutura permissiva à criação de conceitos que possam auxiliar na escrita sobre a improvisação em dança. Assim, Modes of Thoughté como uma âncora para este estudo ao oferecer e situar o conceito de importância. A improvisação em dança pode possibilitar a criação de relações entre a arte e a neurodiversidade, ao fazer

8 If the body is a dynamic constellation in co-composition with the environment, if it is an ecology of practices, and if thought is an active contributor to the feltness of experience, it seems to me that the start point in challeging the body-world split is putting thought in the world. Thought as Kedar experiences it is not "in" his body. It is across experience, in the synesthetic sensations that refute the absolute locatedness of body and world. (Tradução nossa) 
surgir outros modos possíveis de encontro, outros mundos a se expandir na natureza tátil da pele.

Nessa lógica, das pequenas qualidades que as coisas apresentam, por que alguns eventos se destacam no nosso processo de percepção? O conceito de importância, como descrito por Whitehead, "Há sempre um vago além, à espera de penetração em relação aos seus detalhes."9 (1968, p. 38). De tal sentido, a noção de importância é diferenciada da noção daquilo que importa na matéria-de-fato, pois a importância sublima outra condição no tempo da relação sujeito e objeto, um tempo permissivo a uma diluição dos limites, que outrora definiam os contornos de onde começa e de onde termina um sujeito e um objeto.

Se o corpo é uma constelação dinâmica em co-composição com o ambiente, se é uma ecologia de práticas, e se o pensamento é um contribuinte ativo para a percepção da experiência, parece-me que o ponto de partida para desafiar a divisão do mundo e do corpo é colocar pensamento no mundo. O pensamento, como apresentado na experiência de Kedar, não está em seu corpo, está no atravessamento entre experiência e sensações sinestésicas que refutam a localização absoluta do corpo e do mundo.

Portanto, quando utilizo a noção de importância de Whitehead (1968), não me refiro a um sujeito que se importa, voluntariamente, por algo que ele deseja na matéria-de-fato. Me refiro a um vetor de movimento que alça a atenção de algo no sujeito, de modo a encontrar um dentro que se integra com um fora. Ao invés de eu dançar, eu sou dançada por algo que alça minha importância. Isso pode ser praticado por meio de exercícios do contato improvisação, propostas da educação somática, da criação de improvisação em dança pelo estímulo dos sons, das cores de um ambiente, ou até mesmo, de uma pergunta ou de sua resposta.

Por exemplo, no percurso entre minha casa e a universidade, posso escolher no que colocar a atenção, que pode transitar por vários pensamentos ou até mesmo por ouvir uma música. Quando, em um momento específico, a folha de uma árvore começa a cair e viro minha cabeça em sua direção, no exato momento

${ }^{9}$ There is always a vague beyond, waiting for penetration in respect to its detail. (Tradução nossa) 
em que a folha está no ar em queda, percebo-me em queda junto com a folha, nada mais importa, apenas a folha que alçou sua importância sobre minha percepção sensorial. Logo, é possível pensar o cacoete a partir dessa noção de importância, como um modo de apreensão, de reorganização do espaço, ou até mesmo dos afetos que parte dos fenômenos sensoriais.

Brian Massumi, teórico social e filósofo canadense, em seu artigo Arte do corpo relacional: do espelho-tátil ao corpo virtual (2016), reconsidera o conceito de sinestesia espelho-tátil a partir da noção de corpo virtual, ao apontar para as dimensões infinitas multissensoriais do movimento. Ele aponta que, "A experiência, primitivamente, vem como uma continuidade de qualidades intrínsecas de sensações das quais nós, os neurotípicos, só podemos formar uma frágil conexão" (2016, p. 9). Desse modo, sugere uma diferenciação entre uma percepção neurotípica e uma percepção sinestésica, em que a primeira tem uma diagramação mais limitada dos afetos e da interação, enquanto a segunda é possibilidade de outros infinitos virtuais dos sentidos, sendo ambas artes da experiência.

Os territórios invisíveis e as diversas percepções que compõem o tempo/espaço na improvisação em dança, podem ser compreendidos como parte dos territórios qualitativos a serem atualizados no movimento involuntário das pessoas com Síndrome de Tourette. De uma desinibição alçada por uma artisticidade da experiência que é permissiva a uma interpenetração mútua do caos virtual. Seria como se uma organização necessária nesse continuum qualitativo do caos virtual acontecesse, ou se atualizasse, por meio da manifestação do gesto repetitivo, do tique. Eu situo o tique não como o caosprimitivo, tampouco como uma disfunção motora. Mas sim como uma desinibição motora, um modo necessário nessa peculiaridade do movimento para organizar o caos-primitivo, como se fosse possível fragmentar a linearidade motora neurotípica em diversas partes, alterando principalmente a duração do gesto.

Um gesto que é composto por tendências de atualização do movimento que irá co-formar o corpo virtual quando se atualiza. Por exemplo, o piscar de olhos várias vezes ou uma piscadela desconfiada inesperada são gestos que se 
atualizam por meio de um corpo virtual. Com base em uma outra percepção sensorial, assim como numa outra virtualidade, manifestada por meio de uma ecologia dos afetos, acontece a reorganização desse corpo virtual em um gesto atualizado.

Nessa dimensão, o cacoete só é caos, quando em meio à infinidade de atualizações gestuais codificadas por um recorte motor neurotípico que inibe outras organizações do caos-primitivo. Portanto, um medicamento que impede que esse impulso sensório motor venha a acontecer, para que essa pessoa mantenha a correspondência dos seus gestos com o padrão codificado de gestualidade, seria um modo cruel de impedir que essa pessoa possa organizar seu caos-primitivo em meio a intensos e suscetíveis estímulos de movimento, que acontecem 'entre' o virtual e o atual. Portanto, o que poderia ocorrer a partir dos constantes mecanismos de supressão utilizados para inibir a necessidade motora?

A partir da leitura do artigo de Massumi (2016), percebi que o cacoete pode ser também manifestação do continuum qualitativo do caos-primitivo,

Como nós não somos implodidos pela intensidade, não nos perdemos nas dobras virtuais infinitas da experiência potencial? Em uma palavra: pelo movimento. Cada movimento é um corte. Traz determinados elementos da experiência ao relevo, organizando o continuum em tempo real. Originalmente, não é que movamos nosso corpo volitivamente, é nosso corpo que é movido pela variação da experiência de nossas tomadas de decisão (Massumi, 2016, p. 13).

Logo, a improvisação em dança pode possibilitar uma prática experimental dessa multiplicidade qualitativa, ampliando zonas de percepção sensorial e alterando pressupostos sobre o que é um gesto. Massumi define como continuum qualitativo "aquele cuja natureza é a de poder ser cortado, a fim de que apareça a expressão limitada do potencial que possui” (2016, p.12), como as dobras de um origami, constituindo uma ideia de geologia da experiência que não se compõe fundada no conceito de espaço. Porque não é apenas possível de ser estendido, mas permite a percepção do sensorial que não se encadeia em pontos relativos, mas em um território qualitativo. O cacoete é uma manifestação desses cortes, 
dessas dobras, desse continuum qualitativo que antecede a criação do gesto.

Por isso, opto por utilizar a palavra território em vez da palavra espaço e desloco o conceito de "corpo-espaço" de José Gil (2009), para o conceito de “corpo-território”. Na obra de José Gil, ensaísta e filósofo português, vislumbro a possibilidade de pensar o inatingível pelas palavras, ao buscar referências possíveis de estabelecer conexões entre a prática de dança que investigo e as pesquisas teóricas sobre tal prática. Desenvolvo, a partir do livro O Movimento Total de José Gil (2009), estruturas ontológicas da dança que possibilitem tecer práticas do pensamento em ação.

Sobre uma ecologia de práticas, Erin Manning faz a seguinte reflexão. "Dentro da complexidade do movimento se movendo, há um movimento ainda não atualizado pela experiência - José Gill chama de movimento total - e isso é movimento atualizado."10 (2016, p. 117). Assim, ao permitir que um processo artístico me mova e ao mover a criação de um evento coreográfico, pergunto-me, como antes, como o movimento move e cria-se em territorialidade, fazendo atualizar gestos dançados, gestos cotidianos, gestos políticos e gestos inquietos.

Em tal escuta, ao me propor a realizar um processo criativo na condição de um evento coreográfico, vieram-me as seguintes questões: O que tais gestos estão revelando sobre o mundo? O que é expressado? Assim, ao tecer uma composição pelas variedades dos gestos e instaurar territórios para que tais gestos expressem seus sentidos, emoções e sensações, a artisticidade de suas beiras em meio ao evento serve como estímulo para sanar a cultura cis-têmica que permeia a artisticidade do movimento dançado.

\section{Referências}

BARBA, Eugenio. A Arte Secreta do Ator. SP: Hucitec,1995.

${ }^{10}$ Within the complexity of movement-moving, there is movement not yet actualized for experience - Jose Gill calls this total movement - and this is actual movement. (Tradução nossa) 
GIL, José. Movimento Total: O Corpo e a Dança. São Paulo: Iluminuras, 2009.

HOUNIE, Gabriela Ana. MIGUEL, Eurípedes Constantino (Org.) Tiques, Cacoetes e Sindrome de Tourette: um manual para pacientes, seus familiares, educadores e profissionais da saúde. Porto Alegre: Artmed, 2012.

MAGNAVITA, Paqualino R. Gestologia: Breve ensaio sobre uma diferente teoria do gesto. In: Corpocidade 5 - Gestos Urbanos. Salvador: Edufba, 2017, p.150-172.

MASSUMI, Brian. A arte do corpo relacional: do espelho-tátil ao corpo virtual. São Paulo: Galaxia, 2016.

MANNING, Erin. The Minor Gesture. Georgia: Duke University Press, 2016.

MANNING, Erin. Always More than One. USA: Duke University Press, 2013.

ROSÁRIO, M.C; MATHIS, M.A.; MIGUEL, E.C., Tiques, cacoetes, manias, dúvidas e obsessões: Existe uma relação? In: Tiques, Cacoetes e Síndrome de Tourette: um manual para pacientes, seus familiares, educadores e profissionais da saúde. Porto Alegre: Artmed, 2012, p. 29-43.

WHITEHEAD, Alfred North. Modes of thought. New York: The Free Press, 1968.

Recebido em: 07/01/2021

Aprovado em: 19/04/2021 